\section{Провал реформы железнодорожного транспорта: пройдемся по персоналиям}

Е.Б. КИБАЛОВ, доктор эКономических наук, Институт экономики и организации промышленного производства СО РАН, Новосибирск

В статье анализируется неудачная структурная реформа железнодорожного транспорта России. Цитируются исходные установки разработчиков проекта реформы, оказавшиеся несостоятельными, и спорные предложения Минэкономразвития по ее продолжению. Приводятся возражения оппонентов как на стадии обсуждения замысла проекта, так и при обсуждении путей его дальнейшего развития. Формулируются необходимые и достаточные условия продолжения реформы железнодорожного транспорта, обеспечивающие его устойчивое функционирование и эффективное развитие.

Ключевые слова: структурная реформа, железнодорожная отрасль, централизованная модель, вертикально интегрированные дивизионы, Принолярная магистраль

«Я не считаю, что РЖД нужна именно реформа, это не очень правильное слово... Компании необходима программа повышения конкурентоспособности и эффективности».

А. В. Дворкович, заместитель председателя Правительства Российской Федерации ${ }^{1}$

Если вести отсчет с 1998 г., когда была опубликована «Концепция структурной реформы федерального железнодорожного транспорта» ${ }^{2}$, до 2015 г., когда президент корпорации ОАО «РЖД» В. И. Якунин подал в отставку, реформа, задуманная как либеральная, продолжалась 17 лет, т. е. без спешки и в канонах градуализма. Каковы результаты? Процитируем в качестве ответа фрагмент статьи профессора В. А. Кудрявцева.

«Если взглянуть на ситуацию с учетом существующих реалий, то можно сказать, что за годы реформы железнодорожная отрасль из единого отлаженного механизма превратилась в аморфный рынок, а ОАО “РЖД” - из структуры, олицетворяющей

URL: http://www.gudok.ru/infrastructure/?ID=1321402

2Утверждена Постановлением Правительства РФ № 448 от 15 мая 1998 г. эту железнодорожную отрасль, в бесправного участника рынка, поскольку не имела права как государственная структура с повешенным на нее ярлыком “естественная монополия" пользоваться рыночными механизмами. Отрасль в целом оказалась неуправляемой и была ввергнута в пучину хаоса и неразберихи. Никто за состояние и качество работы отрасли ответственности не несет, и государство, экономика и население от этого только проиграли» [1]

Заметим, что цитированный текст, несмотря на некоторое сгущение красок, в главном объективен. Он отражает не только негативные оценки результатов реформы с узкопрофессиональной точки зрения, но и совпадает с аналогичной общественной оценкой ${ }^{3}$ Текст относится к ситуации 2013 г., но сегодня, на наш взгляд, сдвигов к лучшему не просматривается, скорее, наоборот. Реформа, инициированная «младореформаторами» и поддержанная западными кредиторами и экспертами, привела к результатам, обратным ожидаемым. Если конкретизировать оценку профессора В.А. Кудрявцева, то вместо роста конкуренции и качества транспортных услуг существенно выросли тарифы, время оборота выгонов увеличилось, а средняя скорость перевозки грузов - снизилась. Число операторских компаний приблизилось к 2000, что привело к возникновению многозвенной логистики при транспортировке грузов и одновременному снижению надежности их доставки в срок.

Появились трудновыполнимые предложения по радикальному изменению ситуации: либо национализация всего приватизированного, т. е. контрреформа, либо для увеличения пропускной способности сети - триллионные вложения в путь и путевое хозяйство. Ни то, ни другое в ситуации кризиса мировой и отечественной экономик, на наш взгляд, практически невозможно, хотя постановочно небессмысленно. Меняет же Великобритания вектор реформирования своих железных дорог, то решительно их приватизируя, то национализируя. А Китай ежегодно вкладывает в развитие сети железных дорог 100 млрд долл., планируя к 2020 г. построить 50000 км скоростных дорог [4].

${ }^{3}$ См. оценкупромежуточных результатов реформыД. А. Медведевым (бывшим в то время президентом России) [2] и аудиторами Счетной палаты [3] 
Что же происходит сейчас вместо трансформационного маневра, необходимость которого подтверждена всем ходом неудачной реформы? После отставки президента ОАО «РЖД» В.И. Якунина смещены с занимаемых постов и переведены в советники главные фигуры прежнего топ-менеджмента корпорации, а Минэкономразвития готовит мероприятие по элиминированию тяги из состава естественного монополиста. Заметим: никто из отставленных функционеров корпорации публично не отчитался перед общественностью за содеянное, ушли, как говорится, молча. Так сказать, в логике «большого советского стиля»: ты провалил порученное тебе дело, но ты человек системы, ты нам социально близок, а мы своих не бросаем, найдем тебе теплое местечко.

Иное дело - «заготовки» Минэкономразвития РФ (МЭР) предлагающего отобрать у ОАО «РЖД» тягу. Это тоже большой, но либеральный стиль: дробить все более или менее работоспособное, раздробленное - коммерциализировать, и пусть рынок спонтанно все упорядочивает. Не получится - что ж: принимая «решение плохое, но неизбежное [которое] ...обязательно будет принято» ${ }^{4}$, хотели как лучше, а получилось как всегда. То есть ненавязчиво будет объяснено, что это рынок потерпел фиаско, а мы «все в белом», и ровно по Чубайсу боремся с наследием коммунизма на железнодорожном транспорте.

В такой примерно логике г-н Мандрон - директор Департамента государственного регулирования тарифов, инфраструктурных реформ и энергоэффективности МЭР, недавно сделал интересные заявления, в которых упирал на краткое слово «должны». Цитируем.

1. «Мы концептуально в рамках одного холдинга должны разделить операционно и сделать отдельно инфраструктурную компанию и локомотивную компанию, чтобы вскрыть всю неэффективность, которая есть».

2. «РЖД должна заниматься диспетчеризацией, и своих машинистов видеть на локомотивах, но у кого будут эти новые локомотивы - непринципиально».

${ }^{4}$ Из заявления г-на Улюкаева по поводу предстоящей пенсионной реформы [5].
3. «Должно быть три блока - инфраструктура, локомотивы и вагоны в виде ФГК 5 . Все остальные вагоны должны остаться в рынке» [6]

Здесь невольно вспоминается М.В. Ломоносов, стихами убеждавший, «Что может собственных Платонов И быстрых разумом Невтонов Российская земля рождать». Так-то оно так, однако менее известно, что на входе в академию Платона было начертано: «Сюда не войдет не знающий геометрии». А Ньютон утверждал: «Гипотез не измышляю».

С таких высот хочется спросить г-на Мандрона: вы или ваш департамент изучали проблему не очень удачного, скажем мягко, многолетнего реформирования железнодорожного транспорта России? А зарубежный опыт и его пригодность для использования в отечественных реалиях критически анализировали? Если да, то почему до сих пор не поняли, что «геометрия» инфраструктурных отраслей, особенно капиталоемкого железнодорожного транспорта, состоит вовсе не в дроблении и еще раз дроблении, а в необходимости регулярной подпитки железных дорог инвестициями в должном объеме? И что государство как один из главных выгодополучателей эффективно работающего железнодорожного транспорта в условиях немереных российских пространств, освоенных в хозяйственном отношении очагово, не должно «измышлять гипотез», каким образом сэкономить инвестиционные ресурсы на железных дорогах посредством их распродажи по частям?

В ожидании членораздельного ответа посмотрим, что в этой связи говорят еще не отставленные железнодорожники [6].

1. Разделение перевозочной деятельности и инфраструктуры неизбежно приведет к существенному росту трансакционных издержек. «Они будут вызваны технологическим рассогласованием и различием экономических приоритетов деятельности инфраструктурной компании и перевозчиков».

2. Для повышения эффективности перевозочного процесса необходимы консолидация значительной части универсального подвижного состава (полувагонов) у перевозчика и дерегулирование вагонной составляющей в тарифе. «За счет эффекта масштаба, обезличивания парка и гибкости в применении тарифа

\footnotetext{
${ }^{5}$ Акционерное общество «Федеральная грузовая компания».
} 
перевозчик будет иметь возможность своевременно и с наименьшими издержками обеспечивать спрос грузоотправителей на перевозку».

3. Что касается привлечения инвестиций в локомотивную тягу, при существующих объемах предъявления грузов на сети РЖД имеется значительный профицит тягового подвижного состава.

В отличие от речей г-на Мандрона, упертого, на наш взгляд, либерала, представители ОАО «РЖД» мягко намекают ему и его начальству из МЭР: ребята, вы опять, видимо, не в курсе дела, а именно: погрузка на железных дорогах падает, профицит вагонов, созданный вашими же стараниями на предыдущих этапах реформы, имеет место, уже возник профицит локомотивов. И вообще, вы что-нибудь слышали о трансакционных издержках?

Возникает вопрос: куда рулить дальше? Вопрос стратегический, и мы как продвинутые налогоплательщики, за чей, собственно, счет в России уже четверть века производятся невиданные либеральные эксперименты, вправе заявить, по крайней мере, в отношении железнодорожного транспорта: то, что описано выше - рецидив, чреватый коллапсом железных дорог страны. Рецидив потому, что все это уже было, известно чем закончилось (см. выше), и важно напомнить, как все начиналось. Дадим историческую справку.

Из интервью г-на Пекана - генерального директора консалтинговой компании ${ }^{6}$, данного через шесть лет после запуска структурной реформы железных дорог России, когда ее негативные результаты профессионалами уже уверенно прогнозировались:

«...Самый громкий наш проект - это реформирование и преобразование Министерства путей сообщения в ОАО “Российские железные дороги”. Мы разрабатывали вместе с компанией McKinsey программу структурной реформы на железнодорожном транспорте, и организационную структуру новой создаваемой компании, систему управления, технологию управления ...я надеюсь, что он [проект реформы - E. K.] эффективный» [7].

${ }_{6}^{6}$ Закрытое акционерное общество «Аудиторско-консультационнаягруппа "Развитие бизнес-систем"», является партнером компании «Грант Торнтон», работающей в России на рынке аудиторских и консультационных услуг с 1994 г.; в 1998-2015 гг. была членом «Грант Торнтон Интернешнл».
Отвечая далее на вопросы интервьюера, как происходит взаимодействие клиента-заказчика и исполнителя (РБС), Пекан пояснил:

«Это всегда совместное творчество. Степень участия наша в постановке задач каждый раз меняется. Я думаю, что, тем не менее, мы, оказывая в большинстве случаев определяющее влияние в постановке задачи, потому что у нас есть определенный опыт и определенное умение структурировать те проблемы, которые стоят перед бизнесом» ${ }^{7}$.

Таким образом, авторы проекта структурной реформы железнодорожного транспорта персонифицированы. Правда, интересно знать, кто в межкорпоративном авторском коллективе разработчиков был автором, а кто соавтором, но об этом позже.

Сейчас же вернемся к началу реформы и посмотрим, как «совместное творчество» по Пекану и «умение структуризовать проблемы» осуществлялись на деле. Соответствующая информация «вывешена» в Интернете [8].

Итак, слово от имени разработчиков - А. Максимову, бывшему в то время директором по развитию бизнеса РБС, члену Экспертного совета по естественным монополиям Совета Федерации РФ, входит в «ТОП-10» лидеров-руководителей национального рынка аудита и консалтинга. Начинает он точно так же, как много лет спустя г-н Мандрон, упирая на «должны».

1. «Вопросы реформирования железнодорожной отрасли не могут рассматриваться вне общего контекста реформирования естественных монополий. В соответствии с государственной политикой и в железнодорожном транспорте, и, например в электроэнергетике, сетевые инфраструктуры, составляющие большую часть активов отрасли, должнны (курсив наш. - E. К.) остаться в целостном виде в государственной собственности, а выделяются или, назовем своими словами, приватизируются так называемые конкурентные сектора, которые подлежат постепенному дерегулированию».

2. «Принятая логика реформирования естественных монополий диктует (курсив наш. $-E$. $K$.) и соответствующую последовательность действий».

7 Цитируя фрагменты из интервью Игоря Пекана, мы сохраняем грамматику и синтаксис первоисточника [7] 
Дальнейшее цитирование можно было бы прекратить, потому как, коли содержание п. 1 «диктует» все последующие действия, то они же предопределяют результаты, описанные выше и весьма отличающиеся от обещанных. Но процитируем еще одно положение, чтобы зафиксировать все первоначальные «указивки» разработчика заказчику в полном объеме

3. «...Ключевыми вопросами в обозримой перспективе будут являться не вопросы образования крупных региональных транспортных компаний с участием железных дорог - такое мнение высказывает ряд оппонентов (тем более что недопустимость слияния предприятий потенциально конкурентной среды и естественно-монопольного сектора является одним из условий проведения структурной реформы $\left.{ }^{8}\right)$, а вопросы эффективного управления территориальными филиалами ОАО “РЖД“”.

А что же оппоненты-железнодорожники?

1. « ...У большинства опрошенных... по поводу структуры ОАО "РЖД“ лиц основным объектом критики выступал один аспект - лишение железных дорог статуса юридического лица. Основной аргумент: сметно-нормативный принцип финансирования в суперкорпорации ОАО "РЖД“ характерен, прежде всего, своей затратностью. То есть не заинтересованные в росте эффективности работы железные дороги и их подразделения будут не снижать издержки, а напротив, стараться раздувать их в стремлении увеличить свои бюджеты. А это - основной вопрос работоспособности экономической структуры».

2. «В оценках экспертов также подвергается сомнению управляемость такой громадной унитарной структурой, прогнозируется накапливание нерешенных вопросов на местах, звучит мысль о том, что количество обращений в центр компании настолько возрастет, что она не сможет их переваривать».

3. «...При исключительно вертикальном варианте дезинтеграции МПС в ОАО “РЖД“ останется наименее рентабельная деятельность, организованная в некую командно-административную систему, являющуюся тем не менее самоокупаемым

${ }^{8}$ Не очень понятно, каким способом удалось согласовать условие «недопустимость слияния» с партнером - компанией McKinsey, памятуя, что американские железные дороги указанное условие игнорируют и по этой причине (но не только) на порядок более эффективны, чем российские. хозяйствующим субъектом, да при этом еще и основой железнодорожного транспорта страны».

Приведенные цитаты свидетельствуют о том, что народ «зрил в корень» и результаты реформирования по либеральным прописям предсказал точно. Тем не менее приведем высказывания еще двух оппонентов, сомневаться в компетентности которых не приходится.

А.Г. Тулеев, губернатор Кемеровской области:

«С образованием РЖД железные дороги становятся филиалами компании, то есть лишаются статуса юридического лица. $Я$ работал начальником дороги и могу судить, к чему это приведет Без денег - это уже не начальник дороги. Это - или парень на побегушках, или свадебный генерал - как хотите. Получается, что все деньги концентрируются в Москве. Такая ситуация приведет к серьезному замедлению решения насущных вопросов в регионе. Зачем, например, я поеду к начальнику дороги, о чем с ним буду говорить? За жизнь, что ли? Я считаю, что надо, наоборот, укреплять низы, здесь нужно решать максимум вопросов. Как в реформе системы самоуправления - давать сюда больше полномочий и под них - деньги. Иначе центр не справится. Котловой способ собирания и расходования денег мы уже проходили».

С.М. Резер, президент НП «Гильдия экспедиторов», профессор, доктор технических наук, Заслуженный деятель науки и техники РФ:

«В наше время бурного реформирования в спешке, конечно, возможны ошибки и неверные шаги, но того, что очевидно неправильно и вредно, допускать ни в коем случае нельзя. К таким ошибочным предложениям, по моему глубокому убеждению, относится намеченная ликвидация железных дорог в составе ОАО "РЖД“ как самостоятельных юридических лиц. В любой отрасли при осуществлении реформ крайне важно сохранить и укрепить основное производственное звено на местах. Лишь начальник дороги на месте сможет обеспечить привлечение объема перевозок, правильное применение системы тарифов и льготных скидок, ответить на запросы губернаторов, клиентуры, налоговых и других инстанций. Из центра этого эффективно не сделать Также важнейший фактор, кричащий в пользу железных дорог, это безопасность движения. Здесь регулярные осмотры и ответственность на местах со стороны начальников магистралей 
имеют решающее значение. Я думаю, даже если мы допустим эту грубую ошибку, дороги очень скоро (в существующих или в более крупных размерах, в виде округов) обязательно будут восстановлены. Но в процессе такой реорганизации мы потерпим огромные убытки и невосполнимые потери».

Конечно, была и третья группа из числа функционеров бывшего МПС РФ, которая, сообразив, откуда и куда дует ветер, разьясняла и проталкивала либеральной проект реформирования МПС. Сейчас эта группа существенно «зачищена», но не жестко и, по-видимому, советует новому топ-менеджменту ОАО «РЖД» как быть дальше с тем, во что превратилось бывшее МПС РФ.

Действительно, как быть и что делать? Для отечественных железных дорог, на наш взгляд, приемлем в настоящее время иной пореформенный путь, менее контрреволюционный и менее затратный, чем упомянутые выше тотальная приватизация или крупномасштабное инвестирование. Но какой?

Первое необходимое условие его реализации, как представляется, вполне очевидно: при любых моделях управления уровень ограниченности инвестиционных ресурсов, направляемых на поддержание в работоспособном состоянии железных дорог общего пользования, не должен быть ниже некоторого критического порога ${ }^{9}$. Когда железные дороги являлись государственными, как это было в СССР, вопрос решался правительством и руководящими органами КПСС в плановом порядке; теперь, если дороги приватизированы даже частично, государственное регулирование следует устроить так, чтобы провалы рынка, ведущие к недоинвестированию железных дорог, ликвидировались за счет федеральных бюджетных средств. Что естественно: именно государство заинтересовано в политической целостности

${ }^{9}$ О том, каков этот уровень, можно судить по историческому прецеденту. Какписал в своих воспоминаниях С.Ю. Витте об известной железнодорожной аварии в конце XIX века: «Во время крушения государь со своей семьей находился в столовом вагоне; вся крыша столового вагона упала на императора и он только благодаря своей гигантской силе удержал эту крышу на своей спине и она никого не задавила». ( Цит. по http://biofile.ru/his/27413. $\mathrm{html).} \mathrm{Все} \mathrm{это} \mathrm{происходило} \mathrm{до} \mathrm{огосударствливания} \mathrm{российских} \mathrm{железных}$ дорог и явилось следствием крохоборства тогдашних железнодорожных магнатов, экономивших на инвестициях в обустройство железных дорог. страны и получении соответствующих эмерджентных эффектов на макро- и микроуровнях, обеспечиваемых в том числе и сетью исправно функционирующих железных дорог. Поэтому, как ни мал ныне инвестиционный пирог, железные дороги должны получить свою законную долю без задержек и не по остаточному принципу.

Достаточных условий несколько. О некоторых автор с соавторами неоднократно писал, в том числе и в «ЭКО» [8]. Коротко перечислим наиболее важные условия.

1. Необходимо найти компромисс между традиционным взглядом железнодорожников о заведомой эффективности централизованной модели управления единым (экстерриториальным) железнодорожным комплексом и альтернативным представлением отрасли как системы полуавтономных железных дорог региональных вертикально интегрированных (подвижной состав плюс рельсы) дивизионов. Первый шаг на пути к компромиссу предлагался давно, и не только нами. Это расщепление железнодорожной сети России на два блока: европейский - от западной государственной границы до Урала включительно, и азиатский от Омска до Владивостока. Первый блок может работать в рыночно-конкурентной парадигме, копируя любые аналогичные мировые модели: плотность железнодорожной сети и вообще транспортной сети позволяет в Европейской России менять модели управления, как в Англии, было бы желание и доказана целесообразность.

Иное дело второй, азиатский блок. Здесь плотность железнодорожной сети минимальная, несколько бо́льшая - от Урала до Байкала, чем от Байкала до Чукотки и Приморья, но все же конкурентной эта сеть быть не может ни сегодня, ни в среднесрочной перспективе. Тем не менее азиатский блок стратегически важен для России в качестве гаранта национальной безопасности во всех ее аспектах. Следовательно, по нашему мнению, лучше всего, чтобы этот блок управлялся как казенное предприятие, возможно, дополнительно военизированное на манер МЧС С постановкой в качестве важнейшей задачи строительства Приполярной железнодорожной магистрали вдоль Арктического побережья (как развитие проекта «Северный широтный ход») в качестве адекватного ответа на вызовы стран-претендентов на ресурсы Северного Ледовитого океана. 
2. Было бы полезно силами РАН осуществить научный аудит закрытого акционерного общества «Аудиторско-консультационная группа "Развитие бизнес-систем"» и оценить вклад этой фирмы в научное окормление ее российских клиентов. Если окажется, что польза от оказанных ею услуг многочисленным заказчикам самого высокого ранга аналогична рассмотренным результатам проекта структурной реформы железнодорожного транспорта, то неплохо бы по суду, если удастся, взыскать с исполнителя определенные суммы, хотя бы за моральный ущерб. Подобное мероприятие имело бы профилактическое значение при выборе разработчика проекта дальнейшего реформирования ОАО «РЖД».

3. Не помешал бы также аналогичный научный аудит McKinsey \& Company на предмет выяснения эффективности еe деятельности в России на примере разработки проекта структурной реформы железнодорожного транспорта.

4. Что касается МЭР, то неплохо было бы услышать от его руководителя А. В. Улюкаева, в какую сумму обошлась казне провальная реформа железнодорожного транспорта и какие предложения есть у возглавляемого им ведомства по части ее продолжения. Конечно, помимо тех, которые довел до сведения общественности г-н Мандрон.

\section{Литература}

1. URL: http://railway.kanaries.ru/index.php?showtopic=8751 (дата обращения: 07.03. 2016).

2. URL: http://customsexpert.ru/news/reforma-rzhd-provalilas.htm

3. URL: http://www.interfax.ru/russia/357139

4. URL: http://varlamov.ru/1075810.html (дата обращения: 07.03. 2016).

5. URL: http://newsland.com/user/4297846467/content/uliukaevrekomenduet-uvelichit-pensionnyi-vozrast-dlia-zhenshchin-na-8let/5145184

6. URL: https://www.vedomosti.ru/business/news/2015/10/07/611839minekonomrazvitiya-razdelit-rzhd

7. URL: http://www.rbsys.ru/print.php?option=media\&page $=1831$

8. URL: http://www.rbsys.ru/print.php?page=53\&option=media; Быкадоров С.А. Необходим дифференцированный подход к тарифной политике // ЭКО. - 2015. - №10. - С. 145-152.; Кибалов Е.Б. Проблема тарифного регулирования на железнодорожном транспорте // ЭКО. 2015. - № 10. - С. 139-144. 